\title{
HISTÓRIA DA BELEZA E PRÁTICAS EDUCATIVAS DE ADESTRAMENTO DOS CORPOS FEMININOS NO BRASIL
}

\author{
Joedna Reis de Meneses ${ }^{1}$ \\ Azemar dos Santos Soares Júnior ${ }^{2}$ \\ Edna Maria Nóbrega Araújo ${ }^{3}$
}

No final do século $\mathrm{XX}$ os discursos sobre o corpo passaram a ser associados à práticas educativas que enunciavam, dentre outros aspectos, a urgência dos indivíduos se tornarem responsáveis por seus corpos educando-os para a beleza, a saúde e aparência de "boa forma". O cuidado de si, tornou-se gradativamente responsabilidade de cada indivíduo que, para se manter dentro da chamada "boa forma", precisou se submeter a sacrifícios e cuidados. Segundo Paula Sibília, o que se afirma é que a salvação dos corpos, o alcance dessa "boa forma", comumente, pode ser comprado:

A tecnociência vende a promessa de que uma boa gestão de si permitiria superar - ou pelo menos, contornar de maneira transitória, porém efetiva - os problemas acarretados pela nossa indigna condição carnal. Recorrendo às mais diversas técnicas e saberes à venda, nos é dito que tais obstáculos podem ser ultrapassados, eliminados, lipoaspirados. A salvação é individual e pode ser adquirida em prestações, aqui e agora - porém, logicamente, é preciso pagar por elas. ${ }^{4}$

Em um momento no qual os indivíduos se tornaram responsáveis pela sua beleza e boa forma, a luta para que seus corpos se enquadrem e se eduquem através dessa "moral estética" é cotidiana. No mundo cultuado pelas celebridades da Televisão, do cinema e dos reality shows "educativos" das ultimas décadas do século XX os famosos promovem práticas educativas midiáticas que chegam ao universo das pessoas consideradas comuns quando a experiência de um corpo tido como "perfeito" passa a ser perseguida. E, assim como as chamadas celebridades, os

1 Doutora em História pela Universidade Federal de Pernambuco. Professora Associada do Departamento de História da Universidade Estadual da Paraíba, Campus de Guarabira. E-Mail: <joedna8@hotmail.com>.

${ }^{2}$ Historiador, Doutor em Educação pela Universidade Federal da Paraíba. Atualmente realiza estágio pós-doutoral junto ao Programa de Pós-Graduação em História da Universidade Federal de Campina Grande. Professor Adjunto do Departamento de Práticas Educacionais e Currículo da Universidade Federal do Rio Grande do Norte, Campus de Natal. E-Mail: <azemarsoares@hotmail.com>.

${ }^{3}$ Doutora em História pela Universidade Federal de Pernambuco. Professora do Departamento de História da Universidade Estadual da Paraíba, Campus de Guarabira. E-Mail: <edna06@gmail.com>.

4 SIBÍLIA, Paula. "Imagens da beleza pura: o corpo digitalizado". In: Anais do FILE - Festival Internacional de Linguagem Eletrônica. São Paulo: FILE, 2006, p. 137. Disponível em: $<$ http://www.file.org.br/>. 
indivíduos comuns encontram-se induzidos à perseguição de um tipo de corpo, divulgado como ideal.

Neste artigo, propomos analisar a construção histórica destas práticas educativas moldadoras dos corpos femininos, principalmente no Brasil do final do século XX $e$ na primeira década do século XXI. Para tanto, realizamos uma pesquisa nas revistas Veja, Isto É, Dieta Já e Boa Forma, publicadas no período citado.

Uma radicalização compulsiva e ansiosa a empurrou nos últimos dez anos, e a segue empurrando para a tríade abençoada pela mídia: ser bela, ser jovem, ser saudável! Graças à supremacia das imagens, instaurou-se a tirania da perfeição física. Hoje, todas querem ser magras, leves, turbinadas. Num mundo onde se morre de fome grassa uma verdadeira lipofobia. Todas as mulheres parecem querer participar da sinfonia do corpo magnífico, quase atualizando as intolerantes teses estéticas dos nazistas. ${ }^{5}$

Não há exagero nesta última frase de Priore. Tolerância com a feiura, própria ou alheia, não se trata de um aspecto característico das sociedades do final do século XX. As mulheres, ao se encontrarem diante do próprio corpo, através de vitrines $e$ espelhos, visualizam cada parte do seu corpo e, quando a imagem não é identificada com os padrões de beleza divulgados pela mídia, tornam-se "escravas" das dietas, dos remédios, das plásticas, das máquinas e do personal trainer. A constatação da imperfeição traz à tona a ideia de que é possível aperfeiçoar-se sempre, infinitamente ${ }^{6}$.

Ao ser questionada sobre quando a beleza ocupou lugar de honra na vida da brasileira, Mirian Goldenberg afirma:

A valorização de nossas supermodelos a partir da década de $90 \mathrm{fez} \mathrm{com}$ que a cultura da magreza, da juventude e da beleza adquirisse mais força. Ser modelo passou a ser uma aspiração legítima das meninas e um desejo das mulheres. Todas querem ser lindas, magras e jovens como Giseles, Isabelas, Yasmins. É o que o antropólogo francês Marcel Mauss chamou de 'imitação prestigiosa', você imita quem tem prestígio em sua cultura: as modelos, as atrizes siliconadas $e$ plastificadas, as mulheres e os homens de sucesso. ${ }^{7}$

Encantadas com o sucesso e a "perfeição" das modelos, jovens meninas sonham em exibir famosas grifes nas passarelas do mundo. A busca da perfeição representa a

\footnotetext{
${ }^{5}$ DEL PRIORE, Mary. Corpo a corpo com a mulher: pequena história das transformações do corpo feminino no Brasil. São Paulo: SENAC-SP, 2000, p. 70.

${ }^{6}$ Ver: VILLAÇA, Nizia. "Corpo, sentido e imperfeição: a moda como estratégia". In: SILVA, Ignácio Assis (org.). Corpo e sentido: a escuta do sensível. São Paulo: Editora da UNESP, 1996.

${ }^{7}$ CLEMENTE, Folha de S. Paulo, São Paulo, 08 mar. 2005.
} 
existência de um padrão único de beleza. Porém não há como negar que as diferentes mulheres copiam ou buscam copiar o modelo de beleza da atriz, cantora ou modelo que se encontra em evidência na mídia.

Vejamos, assim, a descrição feita pela revista Boa Forma sobre uma cantora de sucesso no Brasil: Claudia Leitte, Idade: 27 anos Altura: 1,68 m Peso: 56 kg Busto: 88 $\mathrm{cm}$ Cintura: $64 \mathrm{~cm}$ Quadris: $90 \mathrm{~cm}$. Ela foi capa da revista Boa Forma e, como todas outras que são capa de revistas, divulgou suas dicas de beleza: "lições de vida da Claudinha que valem para você conseguir o que quiser - inclusive um corpão!".

Uma leitora da mesma revista: "Quando vemos a Claudia Leite maravilhosa desse jeito, não dá vontade de ser igualzinha"? (Enviado por: Andressa Nicolau, $14 \mathrm{fev}$. 2008).

Ser "igualzinha" ou tentar possuir as mesmas medidas das "celebridades" exige das mulheres um grande esforço e em alguns casos as leva a adotar práticas patológicas com vistas à diminuição do peso, o que tem provocado um aumento crescente de distúrbios alimentares como bulimia e anorexia nervosa.

Ou seja, medir o padrão de beleza de uma mulher a partir dos números não é mérito de Pitágoras ou dos artistas renascentistas. A mulher bela entre o final do século XX e início do século XXI deveria possuir as medidas semelhantes às de algumas "celebridades":

Quais as medidas que uma mulher deve ter para integrar o time das coelhinhas da revista americana Playboy, um dos padrões de beleza mais difundidos e cobiçados em todo o planeta? A candidata acertará em cheio com 87,6 centímetros de quadris, 59,6 de cintura e 1,69 metro de altura, torneado em 51,8 quilos, além de muito busto, é claro. Esses números são a média aritmética das medidas de 240 garotas cujas fotos saíram publicadas, entre 1978 e 1998, nos celebrados pôsteres da edição da revista que circula nos Estados Unidos. ${ }^{8}$

Entre os anos de 1978 e 1999, prevaleceu esse modelo de beleza como ideal para as mulheres. Observa-se que as diferenças são mínimas. Esses cálculos são feitos com base no Índice de Massa Corporal (IMC) ou da relação entre as circunferências da cintura e dos quadris?.

\footnotetext{
${ }^{8}$ Veja, São Paulo, 10 jan. 2001.

${ }^{9} \mathrm{O}$ estudo se deu com base no cálculo do índice de massa corporal (IMC), cuja adoção é recomendada pela Organização Mundial de Saúde (OMS). Obtém-se o índice dividindo o peso da pessoa pela sua altura elevada ao quadrado. A faixa considerada normal fica entre 18,5 e 24,9. A média das coelhinhas, em duas décadas, ficou em 18,1, ou seja, abaixo do patamar da OMS. Acima de 25, vêm o sobrepeso e três categorias de obesidade (leve, moderada e mórbida), das quais muitos tentam escapar. Para efeito de comparação, vale citar o IMC de quatro beldades brasileiras de bastante evidência [...]: Gisele Bündchen (16,87), Carla Perez (20,76), Luciana Gimenez $(18,3)$ e Joana Prado, a Feiticeira $(20,76)$. Outro indicador que também pode ser aplicado ao estudo das garotas da Playboy, é o da relação entre a circunferência da cintura e a dos quadris. As 240 garotas da Playboy variaram de 50,8 a 68,6 centímetros na cintura e de 80,0 a 96,5 centímetros nos quadris, ficando numa média geral de 59,6 e 87,6, respectivamente. Entre as brasileiras, a paixão nacional de Carla Perez, com 101 centímetros. "MAGRAS e poderosas: pesquisa revela quais as medidas que fixaram o padrão das
} 
Mesmo quando se trata de obter um corpo tido como belo através de dietas, as mulheres copiam os padrões e receitas das "celebridades". É importante destacar que as celebridades, comumente, aparecem nas capas de revistas quando se encontram em papel de destaque ou com sucesso na mídia, naquele momento. Isso desperta nas mulheres o desejo de possuir corpos idênticos e um padrão de beleza próximo à perfeição. Por isso, as revistas pagam grandes cachês e as artistas dão dicas de beleza, receitas de que dizem fazer uso para manter a boa forma, a saúde e ser feliz.

A revista Quem aponta 50 segredos de beleza das "famosas" e, na capa, já destaca Débora Secco, Aline Moraes, Grazi Massafera, Priscila Fantin, Maria Fernanda Cândido, Angélica, Sabrina Sato e Adriane Galisteu, musas consagradas entre as brasileiras. Além delas, 42 outras mulheres consideradas ícones de beleza ensinam suas receitas. Com tantas "celebridades" "ensinando" seus truques de beleza, existe alguma dúvida em relação à garantia de venda da revista? Se as mulheres não copiam os modelos de beleza das "celebridades", por que as revistas especializadas investem tanto na temática? E por que as revistas Veja e Isto É, consideradas como publicações voltadas supostamente para assuntos políticos, sociais, econômicos $e$ culturais, trouxeram os temas da beleza, longevidade, juventude, dietas, exercícios físicos, com tanta frequência nas suas matérias do final do século XX? Necessidade de ampliar seu público consumidor? Ou seu público consumidor têm, de certa forma, exigido ou solicitado essa discussão?

Outro exemplo das "celebridades" ditando padrões de beleza foi citado por Mirian Goldenberg, em entrevista a Mônica Manir, do "Caderno Aliás" do jornal O Estado de S. Paulo em 02 fev. 2008:

A atriz Angelina Jolie lidera a preferência das mulheres que querem fazer plástica nos lábios. Se o nariz não agrada, dálhe Nicole Kidman. A bunda dos sonhos é a de Jennifer Lopez, mas Juliana Paes também ganha 10 nesse quesito. Essas referências constam de pesquisa da Sociedade Internacional de Cirurgia Plástica e Estética, com 20 mil cirurgiões plásticos de 84 países, entre eles o Brasil. ${ }^{10}$

O corpo ideal, na atualidade, mistura lábios, nariz e nádegas das "celebridades". O desejo de criar uma imagem passível de admiração, com características de beleza internacional, tem levado as mulheres a visitar deferentes clínicas de estética.

Mirian Goldenberg também faz referência aos modelos que predominaram durante o carnaval de 2008 e que servem de padrão para outras mulheres:

Danielle Souza foi representar a natureza da mulher brasileira. Paira a dúvida, porém, se não significou mais uma das fiéis samambaias de tronco malhado, peitudo e bundudo que dominam os desfiles. Samambaias que vingam como

coelhinhas da revista Playboy". Veja, São Paulo, 10 jan. 2001. Disponível em: <http://www2. uol.com.br/veja >. Acesso em: 13 mar. 2008.

${ }^{10}$ Disponível em: <http://miriangoldenberg.com.br/>. Acesso em: 10 abr. 2017. 
ideais de beleza. Escultura para copiar nas mesas de cirurgia plástica. Espécies-modelo. Corpo padrão. ${ }^{11}$

O que têm em comum todas essas mulheres "espécies-modelos", já que são tão diferentes entre si? Sem dúvida, é o corpo sem gordura, malhado e siliconado, pertencente às "estrelas", que serve de espelho para as mulheres brasileiras:

Sim! As famosas ditam o padrão de beleza. Com certeza sim! Só que existe uma grande diferença entre as famosas e nós mortais, é que algumas pessoas podem entrar em paranoia se não tiverem o mínimo de bom senso. Elas vivem da própria beleza, e podem investir muito do que ganham com isto, afinal, vendem a beleza; Considero isto normal, natural pra elas; Queremos mesmo ver gente bonita na TV, nas revistas... O problema é a mulher normal querer ter, ou ser exigida pelos homens e pela sociedade aquele padrão de beleza, se temos uma vida completamente diferente, com outros objetivos e outras atividades... Acho que temos que nos espelhar na beleza das famosas, afinal, são elas que lançam as modas... mas sem excessos... ${ }^{12}$

Cristiana Nunes se considera uma "mulher mortal" e desabafa as dificuldades para atingir a beleza das "famosas". Embora possua a compreensão de que existem muitas exigências da sociedade e especificamente dos homens que cobram o padrão de beleza das "celebridades", há a crença de que as dificuldades se encontram no excesso. As "famosas" são os espelhos. Algumas buscam o exagero, Cristiana Nunes, por sua vez, busca a moda, a adequação da moda das imortais às mortais. Deseja ser expectadora da beleza das "famosas" da TV e evitar o sofrimento de ter que ser uma cópia excessiva.

Diante dos padrões de beleza que são propostos como ideais, $e$ ao ter consciência de que seu corpo não se enquadra dentro desse modelo, observa-se a crescente insatisfação que as mulheres têm com seus corpos $e$, por isso, espelham-se nas "famosas", nas suas dietas, suas dicas de beleza, nos cosméticos que usam, nos tratamentos a que se submetem, etc.

Acredito que as famosas ditem padrões de beleza sim. $O$ problema é que elas vivem com uma super equipe por trás delas (cabelereiros, personal trainer, cirurgião plástico, nutricionista, etc, etc) e estão sempre perfeitas. Ou vai dizer que vc já viu alguma foto de uma celebridade ao acordar, sem maquiagem, ou gordinha, de biquini? Aqui no mundo real, nós, reles mortais, temos que nos esforçar bastante para

\footnotetext{
${ }^{11}$ Disponível em: <http://miriangoldenberg.com.br/>. Acesso em: 10 abr. 2017.

${ }^{12}$ Cristiana Nunes, entrevista disponível em: <http://miriangoldenberg.com.br/>. Acesso em: $10 \mathrm{abr}$. 2017.
} 
ter nosso 'look' legal e mesmo assim, muitas vezes não dá pra chegarmos ao padrão das famosas...Isso é problema? Creio que não! Quem tem problemas são elas, que não podem pisar em falso, porque há a mídia toda atrás... ${ }^{13}$

Carolina Del Roveri, apesar de desejar o padrão de beleza das "famosas", também aponta as dificuldades ao destacar todo um arsenal disponível para que elas sejam "sempre perfeitas". Palavras como: "nós mortais", "mulher normal", "nós reles mortais", "mundo real", "problema", "paranoia" demonstram como Cristiana Nunes e Carolina Del Roveri se sentem diante das cobranças e impossibilidades de se encaixarem nos padrões estéticos das "famosas", apesar de justificarem que, devido à profissão, as musas precisam estar sempre belas. Cristiana Nunes e Carolina Del Roveri se sentem em outro mundo, mas desejam possuir a beleza das "famosas". É o que Mary Del Priore chama de efeito perverso, pois, "além de todas as clivagens econômicas e sociais que existem no Brasil, haveria essa outra: a da estética" 14 .

Se existem pessoas que apontam as dificuldades em obter o "look" da moda, outras, como Leli, já querem saber detalhes sobre como suas musas conseguiram mudar o visual. Nesse sentido, entra em cena o papel desempenhado pela mídia, dando dicas e receitas sobre o que fazem as celebridades para adquirirem ou manterem sua beleza e felicidade. Em muitos casos, elas próprias dão suas dicas nas Revistas ou programas de TV.

Enquanto fazem sucesso na TV, por exemplo, a beleza dessas personagens exibidas diariamente tornam-se objeto de desejos e anseios e daí passam a ser vendidas através do mercado publicitário como sendo possível de ser alcançada por todas as mulheres.

O artifício, segundo Joana Novaes, é esperto em termos econômicos, uma vez que insere em outro tipo de mercado consumidor toda uma camada da população feminina privada dos serviços de academias de ginástica e de práticas dispendiosas. O canal de TV Shoptime e os catálogos em domicílio, com ofertas a preços populares de aparelhos para 'tirar a barriga', cremes para celulite, pastas emagrecedoras, steps, esteiras domésticas são exemplares para ilustrar a lógica de mercado. O modelo, segundo a psicóloga, visa a gratificação imediata, prometendo à consumidora que nada lhe será negado. A beleza é vendida como promessa para todas! $!^{15}$

Um exemplo são as revistas direcionadas ao público feminino, que se propõem a "ensinar como manter e conquistar uma boa forma, trazendo uma série de dicas com

${ }^{13}$ Carolina Roveri, entrevista disponível em: <http://miriangoldenberg.com.br/>. Acesso em: 10 abr. 2017.

${ }^{14}$ DEL PRIORE, Corpo a corpo..., p. 87.

${ }^{15}$ NOVAES apud DEL PRIORE, Corpo a corpo..., p. 92. 
relação a exercícios, nutrição, e como não poderia faltar em uma revista feminina, inúmeras dicas de moda e beleza" 16 .

De acordo com alguns exemplos comuns nestas publicações, as dicas e receitas geralmente são colocadas como sendo as utilizadas pelas "estrelas", especificamente pela que se encontra na capa. As revistas ainda são "recheadas de fotos de artistas 'famosas' e modelos maravilhosas. É um bom incentivo!" ${ }^{7}$.

Nessas revistas são apresentadas desde as dicas mais fáceis, que podem ser desenvolvidas em casa, até as mais complexas. Vão desde sugestões em relação às dietas, indicações calóricas, receitas de alimentos pouco calóricos, tratamentos para celulite, rugas, informações sobre as partes do corpo que devem ser trabalhadas, o tipo de exercício adequado a cada uma delas, a sequência, as novidades sobre as modalidades de ginástica, os novos produtos estéticos, indicações de intervenções como peeling, botox, até as intervenções cirúrgicas mais invasivas, destacando quem fez e onde fez, ou seja, os nomes de clínicas, preços etc.:

Os discursos das revistas femininas estão envoltos em relações de poder, poder de regular as condutas, de dizer como agir, o que comer, que atividades físicas praticar, em que horário $e$ local, que roupas estão na moda, etc. ${ }^{18}$

$\mathrm{O}$ destaque das revistas encontra-se nas fotos $e$ imagens de corpos, na sua maioria, femininos seminus que ocupam todas as páginas das revistas ilustrando as receitas. Nesse sentido, "as revistas, educam, disciplinam e regulam os corpos como qualquer outra instância educativa e são, por isso, concebidas como Pedagogias Culturais" ${ }^{\prime 19}$.

[...] é possível pensar as revistas voltadas para o público feminino, tanto infantil como adulto, como um artefato pedagógico que exerce poder sobre as mulheres e meninas, ensinando técnicas de como lidar com o corpo. Isso porque os discursos das revistas para mulheres e meninas me parece que se equivalem, de alguma forma, repetindo receitas $e$ dicas para atingirem aquele corpo que é representado na mídia como 'ideal'. [...] Não é somente no espaço pedagógico das escolas que os corpos são educados, moldados $e$ governados. Somos constantemente bombardeadas por informações que se pretendem verdadeiras e universais. Nesse sentido, há pedagogia em qualquer espaço em que se efetua educação, em que se ensina aos indivíduos modos de

\footnotetext{
${ }^{16}$ DEL PRIORE, Corpo a corpo..., p. 70.

${ }^{17}$ Boa Forma, São Paulo. Disponível em: <http://boaforma.abril.uol.com.br/>. Acesso em: 26 fev. 2008.

${ }^{18}$ ANDRADE, Santos Sandra. "Mídia impressa e educação dos corpos femininos". In: LOURO, Guacira Lopes; NECKEL, Jane Felipe \& GOELLNER, Silvana Vilodre (orgs.). Corpo, gênero e sexualidade: um debate contemporâneo. Petrópolis: Vozes, 2003, p. 120.

${ }^{19}$ ANDRADE, "Mídia impressa...", p. 119.
} 
proceder, de viver, de fazer, de comprar, de comer, de vestir, de falar; existe pedagogia em qualquer lugar em que o conhecimento é produzido, em qualquer lugar em que exista a possibilidade de traduzir a experiência e construir verdades. [...] Os espaços pedagógicos são vistos, assim, como aqueles lugares onde o poder é organizado e difundido. ${ }^{20}$

Essas informações são colocadas para o público feminino, enfatizando que, mesmo aquele corpo fora da chamada boa forma, pode obter condições de atingi-la a partir das dicas oferecidas. É como se fosse dito para a mulher: você não tem um corpo padrão? Não se preocupe, nós pensamos em diferentes estratégias e estamos aqui para ajudá-la a ter.

Tanto as imagens e propagandas exibidas na televisão quanto as revistas são locais pedagógicos que, de forma sutil, estão a dizer e instituir o que é considerado um corpo belo e saudável. Dessa forma, impõem um padrão de beleza que deve ser conquistado pelas mulheres.

Observou-se que nas revistas Veja e Isto É, mesmo quando as reportagens de capa são relacionadas à beleza, nem sempre, ou apenas raramente as famosas aparecem nas capas. Já as revistas femininas, investem na bela da vez. Seja atriz, cantora ou modelo. Às vezes, a mesma personalidade chega a ser capa de duas ou mais revistas, dependendo do sucesso e, talvez, do cachê cobrado. Como se pode observar nas capas apresentadas, a idade varia. Ou seja, a busca pela beleza e as dicas são para todas as mulheres. No entanto, pelo que foi possivel observar, apesar de existirem algumas capas que exibem mulheres negras, essas constituem uma minoria. Já as obesas não aparecem em nenhuma capa, apenas no interior da revista para ressaltar o antes e o depois.

As representações não são apenas veiculadas pela revista, mas também são nela produzida através dos diferentes saberes que circulam nos textos e imagens que falam de diferentes práticas sociais de embelezamento, condicionamento físico e de saúde. Práticas estas que produzem efeitos de verdades excluindo $e$ incluindo, em diferentes locais sociais, corpos, sujeitos, grupos. ${ }^{21}$

Percebe-se nas imagens que as mulheres exibem seus corpos como troféus. Exibem os bíceps, a panturrilha ou a rígida musculatura do abdômen, o busto siliconado e o bumbum empinado como ícones da perfeição. Exibem a beleza, a jovialidade, a aparência de felicidade, vitalidade, sucesso e do seu poder de atração sexual.

Por trás dos esforços e determinação que elas descrevem como prazeroso, encontra-se toda uma disciplina a que são submetidas cotidianamente.

\footnotetext{
${ }^{20}$ ANDRADE, "Mídia impressa...", p. 108.

${ }^{21}$ ANDRADE, "Mídia impressa...", p. 119.
} 
Nas revistas e manuais, os conselhos de beleza também se tornam mais adeptos à suavidade $e$ ao prazer do embelezamento. Os manuais de beleza começam a ser escritos cada vez mais pelos novos profissionais da beleza: modelos, esteticistas, esportistas, etc. Eles se preocupam menos em reforçar os laços entre a dignidade moral e a beleza e, cada vez mais, em detalhar as regras de embelezamento. Ao invés de fazer o elogio dos antigos modelos de beleza, eles preferem visar o potencial das leitoras, apreendidas a partir de suas especificidades físicas $e$ psíquicas. Emancipados do domínio médico e higienista, os cuidados de beleza se tornam tão sedutores quanto a bela aparência das modelos e artistas que os recomendam. ${ }^{22}$

Como tantas outras mulheres, incentivadas pelos conselhos da revista Boa Forma, a leitora Heloísa Helena, emagreceu "7 quilos, perdeu 5 centímetros de quadril, 3 centímetros de cintura, $10 \%$ de gordura, passou do manequim 42 para o 38, ganhou resistência cardiovascular e... está se sentindo mais linda do que nunca. Tudo isso em apenas dois meses"23.

Discursos como esses fazem parte das revistas mencionadas. Aliás, as revistas são formadas basicamente de exemplos semelhantes a este. Quando são enunciados para mostrar que toda mulher pode ficar bonita $e$, principalmente, que mudar o corpo depende do empenho, exclusivamente dela. As "mulheres-mitos" dão as receitas e as revistas divulgam.

Mulheres belas aconselhando outras mulheres, de modo informal e extremamente didático, quase sussurando-lhes como é bom, fácil e importante se fazer bela, dia após dia. Mulheres famosas que recomendam o embelezamento com a mesma desenvoltura que revelam suas vidas intimas. Mulheres sempre jovens afirmando, com uma ênfase antes nunca vista, que não vale mais a pena sofrer por falta de beleza. $^{24}$

Em nome da beleza, com o passar do tempo, os corpos femininos se livraram do espartilho e do excesso de roupas, emergindo um discurso defensor da necessidade de liberdade das próprias gordurinhas que antes eram comprimidas e controladas pelo aperto da cintura e escondidas pelas vestimentas. No entanto, o suplício do espartilho não foi substituído por um alívio mas, sim, novos sofrimentos e sacrifícios foram construídos. Aos corpos femininos mais volumosos não era aplicada mais a

\footnotetext{
${ }^{22}$ SANT'ANNA, Denise Bernuzzi de. Corpos de passagem: ensaios sobre a subjetividade contemporânea. São Paulo: Estação Liberdade, 2001, p. 135.

${ }^{23}$ UMEDA, Boa Forma, São Paulo, s.d. Disponível em: <http://boaforma.abril.uol.com.br/>. Acesso em: 26 fev. 2008.

${ }^{24}$ SANT'ANNA, Corpos de passagem..., p. 128.
} 
crítica e a proibição dos higienistas que eram contrários ao uso do espartilho. Com o apoio do discurso médico, diante do respeito que apresenta ao orientar as pessoas com o objetivo de garantir a saúde, os corpos femininos passaram a ser literalmente atravessados pelas ginásticas que foram sendo enunciadas como moda e sinônimo de saúde e bem estar. "O corpo humano não parece ter se libertado das dolorosas amarras que ao longo dos tempos o confinaram. Ao contrário, novas e mais poderosas forças socioculturais emergem dispostas a escravizá-lo" 25 .

A ginástica foi difundida como um "conjunto de preceitos e normas de 'bem viver'. A ela se atribuiu a capacidade de potencializar a utilidade das ações, de educar efetivamente o corpo" ${ }^{26}$. Nesse sentido, a escola tornou-se o lugar propício para sua divulgação.

Na Europa, multiplicavam-se os ginásios, os professores de ginástica, os manuais de medicina que divulgavam as vantagens físicas e morais dos exercícios. Segundo Mary Del Priore, "os novos métodos de ginástica investiam em potencializar as forças físicas, distanciando-se do maneirismo aristocrático da equitação ou da esgrima. Nos finais do século, mulheres começaram a pedalar e jogar tênis na Europa" ${ }^{27}$. Obviamente, que essas mudanças não foram aceitas por todos. Muitas críticas surgiram no sentido das mulheres estarem se submetendo às atividades tidas como masculinas e se afastando do seu papel de mãe e dona de casa.

Palavras como educar e potencializar ocultavam a ideia de adestramento dos corpos que a prática da ginástica produz. Os discursos dos médicos e higienistas continuavam oferecendo explicações para as novas formas de esquadrinhamento dos corpos, justificando que as mulheres confinadas em casa eram susceptíveis à histeria, à melancolia e até mesmo ao adultério, uma vez que praticamente "aprisionadas em casa só restava sonhar com amores impossíveis" ${ }^{28}$.

A ginástica ganhou a força do discurso considerado científico e se mostrou dotada de um grande potencial de adestramento dos corpos sob a feição de um potencial "educativo". Ela foi incluída como atividade obrigatória na instituição escolar. Por outro lado, o número de adeptos voluntários ao desenvolvimento de atividades físicas foi crescendo consideravelmente. Não apenas entre as elites, mas também entre os jovens e o operariado, uma vez que se divulgava que através da ginástica era possível evitar o gasto de energia nas demais atividades e cultivar a saúde. Sendo, assim, foi criada e cultivada uma postura de adestramento tida como "benéfica tanto para formar atletas como para melhorar a condição dos fracos"29.

No século XIX, a prática da ginástica/ Educação Física era incentivada para economizar energia. Na atualidade, ela é utilizada para gastar energia, "queimar" calorias, e "manter-se em forma a partir de uma norma que determina o que é a boa forma" ${ }^{30}$.

\footnotetext{
${ }^{25}$ SIBÍLIA, "Imagens da beleza pura...", p. 132-133.

${ }^{26}$ SOARES, Carmen Lúcia (org.). Corpo e História. 3. ed. São Paulo: Autores Associados, 2006, p. 115.

${ }^{27}$ DEL PRIORE, Corpo a corpo..., p. 62.

${ }^{28}$ DEL PRIORE, Corpo a corpo..., p. 63.

${ }^{29}$ DEL PRIORE, Corpo a corpo..., p. 63.

${ }^{30}$ SOARES, Corpo e História, p. 119.
} 
A Europa das primeiras décadas do século XIX é cenário de rupturas marcantes e profundas no modo de conceber $e$ educar o corpo. [...] $O$ modo como os exercícios físicos começaram a ser pensados nesse momento no interior dos Ginásios em Londres, Paris, Berna ou Berlim, por exemplo, indica uma aproximação e uma aliança cada vez mais alargada com a ciência, permitindo, assim, o cálculo de sua intensidade, o calculo de sua dosagem, a medida de seus efeitos. O movimento corporal pode ser calculado, as qualidades físicas como a força, a velocidade, a flexibilidade ou a resistência podem ser previstas e contabilizadas. Do dinamômetro do século XVIII que media a potência dos músculos ao mais atual aparelho para medir quaisquer capacidades ou qualidades físicas hoje, é possível pensar em persistência e em rupturas, que não abandonam a mesma ideia, qual seja, aquela de medir e de calcular o gesto mais íntimo, de esquadrinhar a expressão mais singela, de elaborar uma cartografia da carne e controlar funções e eficácias. ${ }^{31}$

Pensar a Europa no século XIX é pensar em indústrias, grandes cidades, multidão, homens e mulheres destruídos pela miséria, pobres, doentes, prostitutas, ladrões, promiscuidade, caos. Diante deste quadro, é importante pensar nas possíveis táticas que foram empregadas para conhecer, modelar e disciplinar o corpo e, sobretudo, para gerir a população. "O que seriam as ginásticas e o esporte senão pedagogias higiênicas, táticas sempre atualizadas e ressignificadas de investimento no corpo, na intimidade de sua fisiologia, na gestão dos seus desejos"? Nesse sentido, acredita-se que medir o peso, a força, a velocidade, a flexibilidade, a resistência foi uma forma encontrada para "domesticar o corpo e enquadrá-lo em supostas normalidades". Após serem difundidos na Europa, os modelos de ginástica foram estendidos aos países sob seu domínio ou influência, a exemplo do Brasil ${ }^{32}$.

No Brasil, a mulher começou a se dedicar aos esportes no início da República, momento em que as cidades ganhavam ares cosmopolitas, coincidindo com a ampliação dos discursos médico-higienistas que associavam exercícios e saúde. "O sport, antes condenado, tornou-se indicativo de mudanças: Nosso fim é a beleza. A beleza só pode coexistir com a saúde, com a robustez e com a força" ${ }^{\text {" }}$.

Mas robustez e força eram associadas a um corpo esbelto, conseguido através dos exercícios. "A silhueta não é mais aperfeiçoada pela empregada doméstica e o espartilho, como no século XIX, ela se aperfeiçoa pelos bons exercícios e a vontade. Instaurando-se um imperativo: "seja o escultor de sua silhueta"'34.

\footnotetext{
${ }^{31}$ SOARES, Corpo e História, p. 77.

${ }^{32}$ SOARES, Corpo e História, p. 77.

${ }^{33}$ DEL PRIORE, Corpo a corpo..., p. 65.

${ }^{34}$ VIGARELLO, Georges. História da Beleza: o corpo e a arte de se embelezar, do Renascimento aos dias de hoje. Tradução de Léo Schlafman. Rio de Janeiro: Ediouro, 2006, p. 166.
} 
Assim, o cientificismo imperante, no final do século XIX, possibilitou aos médicos expandir o controle sobre a vida das pessoas, normatizando os corpos e os procedimentos, disciplinando e ordenando a sociedade. Os médicos higienistas criaram todo um conjunto de prescrições que deveriam orientar os exercícios femininos.

Deste modo, torna-se imperioso pensar a ginástica como expressão de um pensamento médico em sua constituição no século XIX e sua ampla difusão no século XX, porque '[...] a medicina é um saber-poder que incide ao mesmo tempo sobre o corpo e sobre a população, sobre o organismo $e$ sobre os processos biológicos e que vai, portanto, ter efeitos disciplinares e efeitos regulamentares'. A ginástica é esta pedagogia que incide sobre o corpo individual e auxilia na regulagem do corpo social, na regulagem das populações, é tanto disciplina quanto regulamentação da vida e vai, de certo modo, e em certa medida, dando visibilidade ao que poderíamos denominar corpo sadio, corpo dócil, compondo um denso registro de saberes sempre reelaborados $e$ disseminados. ${ }^{35}$

A ginástica emerge nitidamente como uma prática de adestramento, de esquadrinhamento dos corpos.

As pedagogias são portadoras de preceitos que dão ao corpo uma forma e o esquadrinham para submetê-lo a normas de um modo muito mais seguro que o pensamento. Imagens sugeridas, gestos esboçados induzem, no silêncio, posições $e$ comportamentos. ${ }^{36}$

Disseminada nas escolas, apropriada de forma pedagógica, a ginástica contribuía na elaboração de novos significados para o corpo. A ginástica passou a ser justificada pelo seu caráter educativo, pelo caráter terapêutico e pelo desenvolvimento da força $e$ da beleza. Ela passou a ser associada à saúde, qualidade de vida, longevidade $e$ beleza. Era preciso "oxigenar as carnes, e alegrar-se graças ao equilíbrio saudável do organismo. A elegância feminina começou a rimar com saúde.

O movimento dos corpos contribuiu decisivamente na elaboração dos significados da beleza no século XX. No período entre guerras, "o que faz a beleza é um corpo magro e musculoso que se movimenta com leveza. [...] A silhueta esbelta e esportiva, os membros finos e musculosos sem gordura parasitária e porte energético: aí está hoje o ideal de beleza feminina" 37 .

\footnotetext{
${ }^{35}$ SOARES, Corpo e História, p. 79.

${ }^{36}$ VIGARELLO, História da Beleza..., p. 75.

${ }^{37}$ VIGARELLO, História da Beleza..., p. 150. 
Com o objetivo de divulgar os novos sentidos para corpo e para a beleza, a partir dos anos de 1930, as revistas e tratados de beleza femininos europeus passaram a divulgar o peso e o tamanho considerados como ideais para cada mulher. Todavia, os valores ditados eram alterados com frequência. $\mathrm{O}$ valor do peso ideal foi rebaixado de forma acelerada. Em janeiro de 1929, o peso aconselhado para uma mulher de $1,60 \mathrm{~cm}$, era de $60 \mathrm{~kg}$ enquanto que, em 1939, já era de 51,5 kg.

Escolhido como 'elemento primordial da beleza feminina', o peso mais do que nunca, foi também escolhido como índice de saúde. O excesso de peso será perigoso: curvas de mortalidade e curvas de quilos se cruzam para realçar os riscos sanitários implicados pela 'gordura'. [...] As curvas mais pesadas, até aqui negligenciadas pela ciência, tornaram-se objeto de suas pesquisas que não existiam. ${ }^{38}$

Segundo Carmen Lúcia Soares, a medição do peso de forma constante inaugurou uma forma de olhar e ao mesmo tempo um modo de intervir, "materializando com intensidade, e quase mecanicamente, os processos de conformação dos corpos, trazendo à cena mais claramente o conjunto de saberes e práticas aos quais tem recorrido a pedagogia, assim como os 'sistemas de poder' que ela tem, sucessivamente, colocado em jogo" 39 .

O sobrepeso, a gordura, passou a significar problema de saúde, produzindo o sentido contrário ao de um corpo esbelto e ativo, que passou a ser sinônimo de vida saudável. O excesso de peso tornou-se objeto de debate entre os higienistas e de preocupação entre as mulheres.

Encontrar-se atenta às medidas e ao peso, tornou-se indispensável para enunciar os sentidos do corpo ao longo do século XX. "Nas últimas cinco décadas, o "peso ideal' foi um dos indicadores mais importantes de boa saúde. [...] O que significa que a cinturinha de pilão deixou de ser apenas preocupação estética para se transformar em recomendação médica. O objetivo agora é eliminar aquela 'barriguinha', nociva à estética e à saúde" ${ }^{40}$.

No filme O Diabo Veste Prada, de 2006, há um diálogo entre dois personagens que trabalham para uma revista sobre moda, que ilustra a diminuição, anteriormente mencionada, da silhueta feminina, bem como a preocupação com a alimentação e a vigilância em que todos estão envolvidos quando se trata de observar e "determinar" o peso, o tamanho e o alimento ideal:

Nigel: Creme de Milho. Escolha Interessante. Sabe que o principal ingrediente do creme de milho é a celulite?

Andréa: Então, nenhuma das meninas come nada?

Nigel: Não depois que o 36 virou 38 e o 34 virou o novo 36.

Andréa: Uso 40.

\footnotetext{
${ }^{38}$ VIGARELLO, História da Beleza..., p. 152-153.

${ }^{39}$ SOARES, Corpo e História, p. 81.

${ }^{40}$ NEIVA, Veja, Disponível em: <http://www.veja.com.br/>. Acesso em: out. 2007.
} 
Nigel: Que é o novo 48.

[Andréa derrama um pouco de creme de milho sobre sua roupa e o diálogo continua:]

Andrea: droga.

Nigel: Relaxe. Sei que há mais sintéticos no seu guarda roupa.

Andrea: Ok. Acha que minhas roupas são medonhas. Entendi. Mas não lidarei com moda para sempre... então, por que mudar só por causa desse emprego?

Nigel: Verdade. É o que essa indústria multimilionária quer, não? Beleza interior. ${ }^{41}$

Nessa cena do filme, enquanto o diálogo acima se desenvolve, duas moças esguias acompanham, se olham e, visivelmente, embora em silêncio, demonstram concordar com o posicionamento de Nigel. Assim, a vigilância constante de uns sobre os outros, a apropriação do discurso médico, a mídia, a ginástica e os esportes passaram a atuar em conjunto no sentido de cultuar o corpo dos indivíduos. Passou-se a divulgar a imagem de uma beleza que não era mais "dada por Deus", mas construída por cada mulher. Elas se tornaram responsáveis por sua beleza e saúde, que deveriam ser conquistadas a partir de um modo de vida enunciado como ativo e, absolutamente, disciplinado.

Se o discurso higienista do século XIX determinava a beleza como uma obrigação para a mulher, no final do século XX, é acrescido a esses discursos que ser bela é fácil e é uma questão de opção e de vontade. A mulher passou não apenas a se preocupar com a sua beleza, mas a ser responsável por ela. Nesse sentido, não conseguir dominar o corpo, falhar na dieta, desistir da academia, passou a ser associado a um fracasso individual. Ou seja, veicula-se a ideia de que a beleza está disponível para todas, diante de um mínimo esforço e que a não concretização desse ideal decorrerá, exclusivamente, da incapacidade da mulher.

Por isso, as revistas fazem uma verdadeira apologia às mulheres que conseguem aderir aos conselhos e recomendações fornecidos pelas "famosas" sobre os cuidados com a aparência. O interessante é que não se fala em sacrifícios ou dificuldades vivenciadas para se perder peso, seja 7 ou mais quilos, e sobretudo para manter o corpo adquirido com as dietas, as ginásticas, os remédios, cirurgias, drenagens, sessões de Ultrashape ${ }^{42}$, etc. As próprias atrizes e modelos não falam das dificuldades que enfrentam para manter a forma; descrevem apenas a "felicidade" que essa chamada boa forma proporciona. As revistas vendem um padrão de beleza específico, como forma de a mulher ter sucesso e ser feliz.

Enfim, não são poucas as estratégias $e$ os discursos elaborados e divulgados em nome do culto ao corpo dirigindo-se, por exemplo, à valorização da eterna juventude,

\footnotetext{
${ }^{41}$ O DIABO veste Prada [The Devil wears Prada]. Direção de David Frankel. Roteiro de Aline Brosh McKenna, baseado em romance de Lauren Weisberger. Los Angeles: Twentieth Century Fox, 2006.

${ }^{42}$ Tratamento estético que elimina a gordura por meio de ultrassom focal, conhecido por Ultrashape.
} 
à associação da saúde com beleza e desta com felicidade. Ter um corpo perfeito, trabalhado, esculpido à imagem $e$ semelhança do desejo de cada um/a é uma tendência que vem se firmando, fazendo parecer serem normais, inerentes, essenciais, portanto, 'naturais' do viver a identidade contemporânea. Já não basta apenas ser saudável: há que ser belo, jovem, estar na moda e ser ativo. Há que ter um estilo criado e valorizado consoante às possibilidades $e$ às informações disponíveis a quem quiser acessá-las. A opção é individual e depende do esforço, da dedicação, da disciplina e dos cuidados de cada um/a para construí-lo. ${ }^{43}$

Segundo Vigarello, foi a partir do período entre-guerras que surgiu a ideia de que seria possível transformar a deusa do cinema, até então inacessível, em objeto acessível e possível de ser imitado. "Por que não se inspirar nelas"? A partir daí, os conselhos das "estrelas" sobre beleza tornaram-se preciosos e passaram a ser divulgados pelas revistas. "A metamorfose se concretiza. Maquiagem, penteado, roupa aproximam bruscamente a jovem banal da estrela de cinema. A transmutação é possivel: Conclusão de tudo isso? Não há mulher feia... Só há mulheres que se descuidam".

Ainda segundo Vigarello ${ }^{44}$, as revistas multiplicaram-se a partir dos anos 1960 e a publicidade passou a ocupar de $60 \%$ a $70 \%$ das páginas de Elle, Vogue ou Jardin des Modes. Também aumentou o público leitor: "quase uma mulher em duas compra revistas desde 1980. O que significa que elas são lidas por duas mulheres em três".

Aqui no Brasil não foi diferente. Nas últimas décadas do século passado e primeira década e meia do século XXI aumentou consideravelmente o número de revistas disponíveis no mercado e seus preços são acessíveis, o que facilita o acesso de um público pertencente aos diferentes segmentos sociais, tendo como consequência um acréscimo das práticas esteticistas a uma escala desconhecida até então, conforme aponta Vigarello:

É preciso insistir sobre essa massificação. Uma vertigem de consumo a acompanha, com o embelezamento se tornando pela primeira vez uma prática tão diversificada como generalizada: a cifra de negócios apenas dos produtos de beleza quadruplicou de 1965 a 1985, a dos cosméticos em geral duplicou de 1990 a 2000, passando de 6,5 bilhões a 12 bilhões de euros; as vendas dos circuitos de distribuição de vários cosméticos corporais aumentaram de 40 a $59 \%$ de 2000 a 2001. O número de salóes de beleza sextuplicou de 1971 a 2001, passando de 2,3 mil a 14 mil, e o das

43 FIGUEIRA, Machado Luiza Márcia. "A revista Capricho e a produção de corpos adolescentes femininos". In: LOURO, Guacira Lopes; NECKEL, Jane Felipe \& GOELLNER, Silvana Vilodre (orgs.). Corpo, gênero e sexualidade: um debate contemporâneo. Petrópolis: Vozes, 2003, p. 126.

${ }^{44}$ VIGARELLO, História da Beleza..., p. 173. 
operações de cirurgias estéticas, calculadas em milhares anualmente entre as duas guerras, contam-se hoje em centenas de milhares. ${ }^{45}$

Seguramente, no Brasil, não tem sido diferente. A busca pelo embelezamento tem levado ao aumento do consumo de produtos de beleza, de cosméticos, das clínicas de estética, do número de cirurgias plásticas, dos salóes de beleza, dos programas de TV voltados para a beleza feminina, da formação de profissionais, e das práticas consideradas alternativas. A massificação revolucionou as aparências, uma vez que esses cuidados encontram-se à disposição das mulheres dos diferentes segmentos sociais. As mulheres mais pobres leem revistas (algumas revistas têm preços populares), frequentam salóes de beleza, maquiam-se, compram cosméticos $e$ algumas ainda se submetem às cirurgias plásticas divididas em suaves prestações.

Na verdade, os anos 50, e sobretudo a década seguinte, representam uma época de transformações acelerada para a história do embelezamento no Brasil: modernização das técnicas de produção de perfumes e de cosméticos, ampliação do mercado de produtos industrializados ligados ao conforto e aos cuidados corporais, a batalha da beleza pretende ser, mais do que nunca, uma luta pessoal e cotidiana, que diz respeito não apenas às mulheres da elite mas também às funcionárias públicas, secretárias, professoras e donas de casa. [...] Não há mais um momento especial para se fazer bela já que todos os momentos devem ser conjugados com um trabalho sobre si mesmo de conquista da beleza e de prevenção da feiúra. ${ }^{46}$

Assim como na Europa, segundo aponta Vigarello, no Brasil, a partir de meados do século $\mathrm{XX}$, associado ao momento de industrialização do país, aconteceu todo um investimento no mercado de produtos direcionados ao embelezamento. Os investimentos no consumo de produtos voltados ao embelezamento começam ainda na infância, com o lançamento de maquiagem e acessórios assinados pelas "famosas" apresentadoras infantis como Xuxa, Angélica ou Carla Perez, estende-se para os préadolescentes e adolescentes, que acompanham a moda dos adultos desde a maquiagem às cirurgias estéticas, bastante comuns nos anos 1990.

Nota-se que o investimento sobre os corpos tem início ainda na infância quando, através de todo um jogo de sedução da mídia, estimula-se não apenas o consumo de certos produtos, mas de uma imagem que deve ser construída pela criança.

Os corpos são educados por toda realidade que os circunda, por todas as coisas com as quais convivem, pelas relações que se estabelecem em espaços definidos e delimitados por atos

\footnotetext{
${ }^{45}$ VIGARELLO, História da Beleza..., p. 173-174.

${ }^{46}$ SANT'ANNA, Corpos de passagem..., p. 130.
} 
de conhecimento. Uma educação que se mostra como face polissêmica e se processa de um modo singular: dá-se não por palauras, mas por olhares, gestos, coisas, pelo lugar onde vivem. ${ }^{47}$

Nesse caso, a pedagogia está voltada para "educar" o corpo não "por palavras, mas por olhares e gestos". Pois, "as pedagogias são portadoras de preceitos que dão aos corpos uma forma e os esquadrinham para submetê-los às normas, seguramente mais ainda que o pensamento" 48 .

Foi a partir da perspectiva de sujeição e não de liberdade que as práticas educativas do corpo ganharam evidência nas sociedades do século XX. Todas as intervenções que se operaram sobre ele enunciava uma suposta liberdade de movimentos. Todavia, ao mesmo tempo, estas intervenções estabeleceram diferentes estratégias de autocontrole.

Os enunciados das medidas dos corpos esquadrinhados pela prática da educação física possibilitaram a emergência de uma preocupação constante com o corpo, com a "boa aparência" e com a beleza. A partir das primeiras décadas do século XX, as práticas de adestramento dos corpos produziram novos sentidos para se pensar o conceito de beleza e este, por sua vez, engendrava novos sentidos para os corpos femininos e suas formas de expressão no século XX e início do século XXI. Sentidos efêmeros, assim entendemos, mas que ajudaram a promover a educação dos corpos femininos a partir de práticas discursivas voltadas para o ideal de beleza que buscamos historicizar neste artigo.

\section{$\operatorname{son}$}

${ }^{47}$ SOARES, Corpo e História, p. 110.

${ }^{48}$ VIGARELLO, História da Beleza..., p. 112. 


\section{RESUMO}

Neste artigo propomos analisar a construção histórica das práticas educativas moldadoras dos corpos femininos, principalmente no Brasil do final do século XX e na primeira década do século XXI. Para tanto, realizamos uma pesquisa nas revistas Veja, Isto É, Dieta Já e Boa Forma, publicadas no período citado. Os sentidos produzidos nos discursos enfatizam o pensamento de que a aparência convencionada como sendo a da beleza está ao alcance de todas as pessoas. Eles enunciam a ideia de uma liberdade de escolha que, de fato, procura aprisionar o conceito de beleza em um único sentido vitorioso: o da perfeição. A multiplicidade da palavra beleza procura ser colocada no esquecimento $e$, de certo modo, se aposta em um movimento anti-histórico que, aparentemente, procura determinar uma nova essência para os sujeitos a ser encontrada nos perfis de beleza difundidos.

Palavras Chave: Corpo; Práticas Educativas; Beleza.

Artigo recebido em 15 out. 2017.

Aprovado em 14 nov. 2017.
ABSTRACT
This paper analyzes the historical construction of educational practices that shape female bodies, especially in Brazil at the end of the $20^{\text {th }}$ and in the first decade of the $21^{\text {st }}$ century. To do that, is conducted a survey in the magazines Veja ("Look"), Isto É ("That Is"), Dieta Já ("Diet Now") and Boa Forma ("Good Shape"), published in the cited period. The sense produced in their speeches emphasizes the view of the good appearance and beauty is within range of all people. They enunciate the idea of a freedom of choice that, in fact, seeks to imprison the concept of beauty in a single victorious sense: perfection. The multiplicity of the word beauty seeks to be put into oblivion and, somehow, bets on an anti-historical movement which, apparently, seeks to determine a new essence for the subjects to be found in the diffused beauty standards.

Keywords: Body; Educational Practices; Beauty. 